ACTA C H EMICA SCANDINAVICA 8 (1954) $937-940$

\title{
Hyaluronic Acid
}

\section{On the Molecular Shape of Potassium Hyaluronate *}

\author{
C. E. J E N S E N
}

Kobenhavns Universitets fysisk-kemiske Institut, Copenhagen, Denmark

\begin{abstract}
Corresponding values of specific viscosities of solutions containing $1 \mathrm{mg}$ potassium hyaluronate in $1 \mathrm{ml}$ are plotted against experimentally determined molecular weights. The graph is in agreement with Staudinger's relation which is valid for flexible linear molecules.
\end{abstract}

Tt was realized rather early that a relation must exist between the symmetry Iof suspended macromolecules and the viscosity of a colloid colution 1,2. The macromolecules are turned and twisted in Brownian motions with the consequence that the molecules appear to occupy a larger volume than they actually do. The streamlines of flow are interrupted on account of the twisting of the particles, and an additional expenditure of energy is needed to maintain a given velocity of flow, which is manifested as an increase in the viscosity.

The relation between particle symmetry and viscosity is complicated and has been treated theoretically by a number of workers ${ }^{3-8}$. Staudinger ${ }^{9}$ investigated the problem from an experimental point of view using a series of long-chain hydrocarbons dissolved in inert solvents. He found that for dilute solutions, the specific viscosity, $\eta_{\mathrm{sp}}$

$$
\left(\eta_{\text {sp }}=\frac{\eta_{\text {sol }}}{\eta_{\text {solv }}}-1\right)
$$

is a function of the number of submolecules ("Grundmoleküle", e.g. $\mathrm{CH}_{2}$ groups in a paraffin chain) contained in the chain - the degree of polymerisation. According to Staudinger the equation $\eta_{\mathrm{sp}}=K \cdot P \cdot c$ is valid for randomly coiled flexible long-chain molecules. In this formula $K$ is a constant for a given series of compounds, $P$ is the degree of polymerisation, and $c$ is the concentration by weight.

Part I: Acta Chem. Scand. 3 (1949) 584; Part II: Ibid. 7 (1953) 603; Part III: Ibid. 8 (1954) 292; Part IV: Acta Pharmacol. Toxicol. 10 (1954) 83.

Acta Chem. Scand. 8 (1954) No. 6 


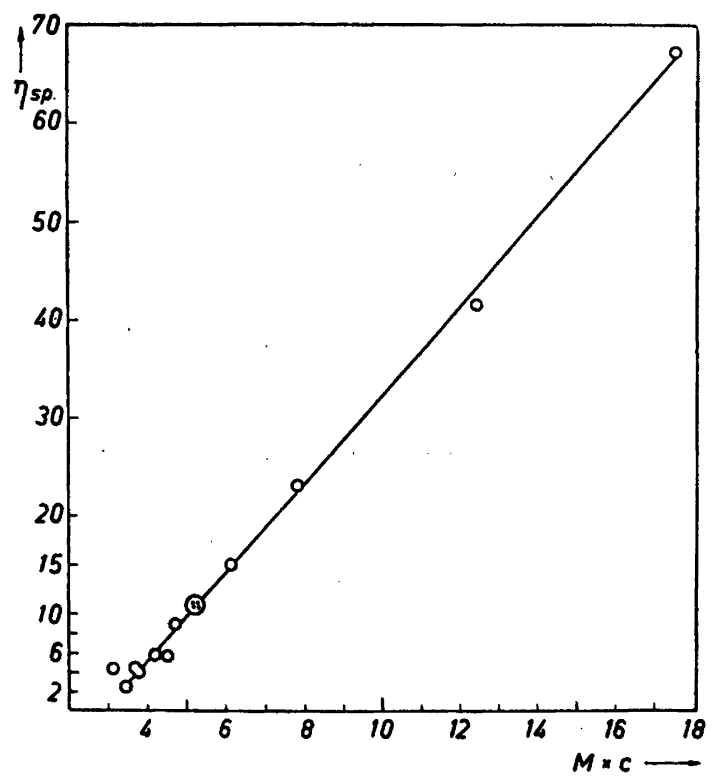

Fig. 1. The graph shows the relation between the specific viscosity (ordinates), and the product of molecular weight and concentration by weight (abscissae).

In the experiments to be reported here the degree of polymerisation $(P)$ is replaced by the molecular weight, and the Staudinger equation is thus converted to: $\eta_{\mathrm{sp}}=K \cdot M \cdot c$. The chemical characteristics of most specimens of potassium hyaluronate are given in recent papers by the author ${ }^{10-13}$. The preparations of potassium hyaluronate are of different origin: human umbilical cords, bovine synovial fluid, human pseudomucinous ovarian cysts, and the endolymph of the labyrinths of sharks. The methods of isolation have also been varied. The relative viscosities at a concentration of $1 \mathrm{~g} / 1$, and at the temperature of $20.0^{\circ} \mathrm{C}$ are determined by a Kvorning and DalgaardMikkelsen ${ }^{14}$ viscosimeter, and the molecular weights by an inverted microosmometer recently constructed by J. A. Christiansen and the author ${ }^{15}$. As seen from Fig. 1 the experimental data fit in with the Staudinger formula, and thus it is reasonable to conclude that the molecular shape of hyaluronic acid is of the flexible long-chain type.

Attention is drawn to the fact, that opinions are still at variance as regards the validity of Staudinger's viscosity rule ${ }^{16}$, but it is of special interest to the present investigation that a great number of cellulose derivatives conform closely to this empiric rule ${ }^{17}$. On account of the great constitutive similarity between hyaluronic acid and various cellulose derivatives we may believe in the validity of Staudinger's rule also as regards hyaluronic acid.

Another observation which favours the assumption of a lcng-chain shape for the molecules of hyaluronic acid is the fact that our experimental data do not fit into the well-known expression of Einstein: $\eta=\eta_{0}(1+2.5 \Phi)$, which 
Table 1. Relation between specific viscosity and molecular weight of different preparations of potassium hyaluronate.

$$
\text { Relative viscosity Specific viscosity Molecular weight }
$$

$\begin{array}{rrr}3.61^{2} & 2.61 & 3.42 \\ 4.93^{1} & 3.93 & 3.75 \\ 5.46^{1} & 4.46 & 3.16 \\ 5.75^{2} & 4.75 & 3.67 \\ 6.99^{2} & 5.99 & 4.12 \\ 6.40^{3} & 5.40 & 4.53 \\ 10.04^{3} & 9.04 & 4.61 \\ 11.80^{1} & 10.80 & 5.17 \\ 11.91^{1} & 10.91 & 5.30 \\ 12.12^{1} & 11.12 & 5.27 \\ 12.19^{1} & 11.19 & 5.16 \\ 16.10^{3} & 15.10 & 6.11 \\ 24.24^{4} & 23.24 & 7.89 \\ 42.81^{3} & 41.81 & 12.42 \\ 68.46^{1} & 67.46 & 17.50\end{array}$

1) Preparations from human umbilical cords

2) " bovine synovial fluid

3) " human ovarian cysts

4) "

is based upon the assumption of spherical rigid particles ( $\Phi$ is the volume fraction occupied by the dispersed particles). We get according to Einstein

$$
\eta / \eta_{0}-1=K_{\text {Einstein }} \cdot c
$$

and according to Staudinger

$$
\eta / \eta_{0}-1=K_{\text {Staudinger }} \cdot M \cdot c
$$

The fundamental difference between these expressions is evident.

Financial support from Det teknisk-videnskabelige forskningsraad and Carlsbergfondet is gratefully acknowledged. The author's very sincere thanks are due to Professor J. A. Christiansen for his help and interest in this investigation.

\section{REFERENCES}

1. Einstein, A. Ann. Physik 19 (1906) 289.

2. Einstein, A. Ann. Physik 34 (1911) 591.

3. Jeffery, G. B. Proc. Roy. Soc. (London) A 102 (1922) 161.

4. Eisenschitz, R. Z. physik. Chem. A 163 (1933) 133.

5. Kuhn, W. Kolloid-Z. 76 (1936) 258.

6. Huggins, M. L. J. Phys. Chem. 42 (1938) 911.

7. Huggins, M. L. J. Phys. Chem. 43 (1939) 439, 1083.

8. Simha, R. J. Phys. Chem. 44 (1940) 25.

9. Staudinger, H. and Heuer, W. Ber. 63 (1930) 222.

10. Jensen, C. E. Acta Chem. Scand. 3 (1949) 584.

11. Jensen, C. E. Acta Chem. Scand. 7 (1953) 603. 
12. Jensen, C. E. Acta Pharmacol. Toxicol. 10 (1954) 83.

13. Jensen; C. E. Acta Chem. Scand. 8 (1954) 292.

14. Dalgaard-Mikkelsen, S., Kvorning, S. A. and Rasbech, N. O. Skand. Veterinär-tidskrift 42 (1947) 661.

15. Christiansen, J. A. and Jensen, C. E. Acta Chem. Scand. 7 (1953) 1247.

16. Meyer, K. H. and Wijk, A. Helv. Chim. Acta 18 (1935) 1067.

17. Schulz, G. V. J. makromol. Chem. (3) 1 (1944) 149, cited from Kruyt, H. R. Colloid Science, Elsevier Publishing Company, Inc., Amsterdam, 1949.

Received March 10, 1954. 